\title{
Effects of Hyperoxia on the Arousal Response to Upper Airway Obstruction in Lambs
}

\author{
SUSAN B. BAKER AND JAMES E. FEWELL \\ Perinatal Research Laboratory, Department of Pediatrics, University of Arkansas for Medical Sciences, Little \\ Rock, Arkansas 72205
}

\begin{abstract}
Experiments were done to investigate the effects of increased inspired oxygen on the arousal response from sleep to upper airway obstruction in 10 newborn lambs. Each lamb was anesthetized and instrumented for recordings of electrocorticogram, electrooculogram, nuchal and diaphragm electromyograms, and measurements of systemic arterial blood pressure and oxygen saturation (fiberoptic catheter oximeter). A tracheotomy was performed and a fenestrated tracheostomy tube was placed in the trachea. A 5F balloon tipped catheter was inserted into the tube so that airflow could be obstructed by inflating the balloon. No sooner than 3 days after surgery, measurements were made during a control period and during an experimental period of upper airway obstruction; the inspired oxygen fraction was alternated hourly between 0.21 and 0.60. A total of 57 epochs of quiet sleep and 58 epochs of active sleep was obtained in eight lambs. Arousal was significantly delayed $(p<0.005)$ during active sleep $(21 \pm$ $6 \mathrm{~s}$; mean $\pm 1 \mathrm{SD})$ compared to quiet sleep $(7 \pm 2 \mathrm{~s})$ in room air. Increased inspired oxygen significantly delayed arousal $(p<0.05)$ during active sleep $(47 \pm 25 \mathrm{~s})$, but had little effect on arousal in quiet sleep $(10 \pm 4 \mathrm{~s})$. These results provide evidence that arousal from active sleep following upper airway obstruction in lambs is primarily initiated by a decrease in arterial oxygen. However, arousal from quiet sleep following upper airway obstruction in lambs appears to be initiated by other stimuli. (Pediatr Res 21: 116-120, 1987)
\end{abstract}

\section{Abbreviations}

UAO, upper airway obstruction

$\mathrm{FIO}_{2}$, fraction of inspired oxygen

$\mathrm{SaO}_{2}$, arterial hemoglobin oxygen saturation

QS, quiet sleep

AS, active sleep

The arousal response from sleep, once characterized as "the forgotten response to respiratory stimuli" (1), is an important protective response that may prevent death during an apneic episode. Although apnea occurs to some extent in almost all preterm (2) and term (3) infants, little is known about the mechanism(s) that initiates the arousal response and terminates

Received February 24, 1986: accepted September 11, 1986.

Correspondence and request for reprints to James E. Fewell. Ph.D.. Department of Pediatrics. Slot 512B. University of Arkansas for Medical Sciences, 4301 West Markham Street. Little Rock. AK 72205.

Supported by a Grant-in-Aid to J.E.F. from the Arkansas Affiliate of the Amcrican Heart Association. S.B.B. supported by a Research Training Fellowship from the American Lung Association. J.E.F. is an Established Investigator of the American Heart Association. the apneic episode. Recently, evidence has been provided that infants with life-threatening apnea have an abnormal arousal response to hypoxemia when compared to normal infants (4). Furthermore, several investigators have suggested that recovery from apnea by arousal or simple resumption of breathing is the crucial vulnerability of infants who die from the sudden infant death syndrome $(1,5)$.

Studies on adult humans and dogs have provided evidence that the arousal response from sleep to upper airway obstruction (pharyngeal and tracheal, respectively) is primarily mediated by the peripheral chemoreceptors $(6,7)$. However, studies on newborn lambs have provided preliminary evidence that the arousal response to upper airway obstruction (tracheal) may be mediated by different mechanisms in quiet sleep and active sleep (8). It was the purpose of the present study to investigate further the mechanism(s) of the arousal response from sleep to upper airway obstruction in newborn lambs.

\section{METHODS}

Ten lambs ranging in age from 8 to 17 days were studied. Each lamb was separated from its ewe 1 to 2 days after birth and was housed in our laboratory in a plexiglass cage $(3 \times 4 \mathrm{ft})$ with continuous access to milk (Lamb Milk Replacer, Land O'Lakes, Inc., Fort Dodge, IA) via a teat mounted on one wall of the cage. The lambs were among other lambs and fed and slept ad libitum.

Each lamb underwent one operation prior to study. For surgery, each lamb was given atropine sulfate $(0.2 \mathrm{mg} / \mathrm{kg}$ subcutaneously) and Ketamine $\mathrm{HCl}(10 \mathrm{mg} / \mathrm{kg}$ intramuscularly) and the trachea was intubated with a cuffed endotracheal tube. Anesthesia was maintained by ventilating the lamb's lungs with $0.5-$ $1.0 \%$ halothane (Fluothane) in oxygen and nitrous oxide $(3: 1)$. An electrocardiogram and rectal temperature were monitored during surgery; body temperature was kept as near $39^{\circ} \mathrm{C}$ as possible with a heating pad.

The operation was done between 5 and 14 days of age. A double-lumen fiberoptic catheter oximeter (model U440 Opticath, Oximetrix, Inc., Moutain View, CA; $90 \%$ response to a step change in $\mathrm{SaO}_{2}$ within $5 \mathrm{~s}$ ) was inserted to the thoracic aorta via a femoral artery for continuous measurement of hemoglobin oxygen saturation and blood pressure. Electrodes were implanted for recordings of electrocorticogram, electrooculogram, and nuchal and diaphragm electromyograms for behavioral staging as previously described (Fig. 1) (9). A tracheotomy was also performed and a fenestrated tracheostomy tube (Shiley, Inc., Irvine, $\mathrm{CA})$ placed in the trachea. Following surgery, the lambs were allowed to recover in a Shor-Line intensive care unit for small animals (Schroer Manufacturing Company, Kansas City, MO) and were then placed in a plexiglass study cage $(2 \times 3 \mathrm{ft})$ in our sleep laboratory but were not studied before the 3 rd postoperative day. The lambs received antibiotics (procaine penicillin $G$ $100,000 \mathrm{U} / \mathrm{kg}$; gentamicin sulfate $2 \mathrm{mg} / \mathrm{kg}$ ) for 5 days beginning on the day of surgery. 

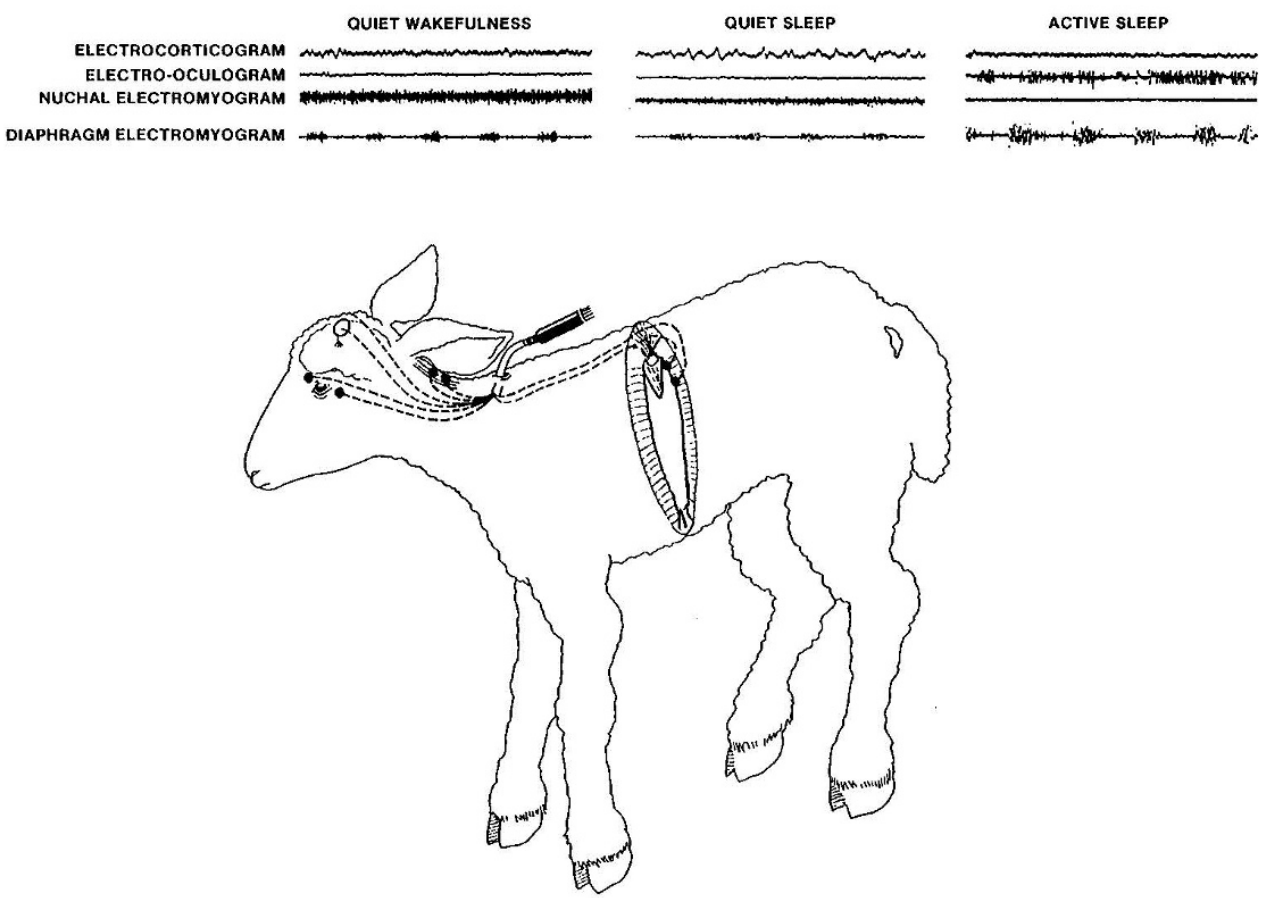

Fig. 1. Drawing of lamb showing placement of electrodes for recordings and actual tracings showing effect of behavioral state on electrophysiological variables.

Prior to a study, a partition is placed in the plexiglass cage to prevent the lamb from turning around once the catheter, breathing circuit, and electrodes are connected. However, the lamb can still lie down, stand up, and feed ad libitum. For a study, the vascular catheter is connected to a strain gauge manometer (Gould P23ID, Gould, Inc., Oxnard, CA) using rigid pressure monitoring tubing and the optical connector is connected to the optical module of the oximeter processor; the strain gauge manometer is placed at the approximate level of the heart when the animal is lying down. The inner cannula is placed into the tracheostomy tube and a breathing circuit (Neonatal Ventilator Circuit, model 5302, Intec Medical Inc., Blue Springs, MO) attached so that 10 LPM of a known gas (i.e. 21 or $60 \%$ oxygen) can be passed by the tracheostomy tube. The tip of a balloon tipped catheter (5F Swan-Ganz, Edwards Laboratory Inc., Anasco, Puerto Rico) is placed through the t-piece of the breathing circuit into the body of the tracheostomy tube so that airflow can be obstructed by inflating the balloon. The electrical plug from the electrodes is connected to an 8 channel backpac preamplifier which is secured to the animals back with stockinette. Electromyograms are band pass filtered $(20$ to $1000 \mathrm{~Hz})$ and the electrocorticogram and electrooculogram are high pass filtered $(0.5 \mathrm{~Hz})$. Using pressure monitoring tubing, the catheter lumen leading to the balloon is connected to a $3-\mathrm{ml}$ syringe located in the recording room. This is done so that the upper airway can be obstructed without the procedure per se arousing the lamb.

Ten lambs were studied to determine whether or not hyperoxia affects the arousal and cardiorespiratory response to upper airway obstruction. During a study, systemic arterial blood pressure, hemoglobin oxygen saturation, and the electrophysiological signals were recorded on a Grass model 7 polygraph (Grass Medical Instruments, Quincy, MA) and the lambs were monitored on a closed-circuit video system. During each sleep state, measurements were made during a 1-min control period and during an experimental period of airway obstruction during 57 epochs of QS and during 58 epochs of AS. Airway obstruction was initiated by inflating the balloon at end-expiration and was terminated by deflating the balloon once the animal aroused from sleep. Because the mean epoch lengths of QS and AS of chronically instrumented lambs during this age range are 6 to 7 and 3 to 4 min, respectively (Johnson J, unpublished data), control measurements were made approximately 2 to $3 \mathrm{~min}$ after the lamb entered QS and approximately $30 \mathrm{~s}$ after the lamb entered AS. The $\mathrm{FIO}_{2}$ was alternated hourly between 0.21 and 0.60 .

For every animal, we determined an average value for each variable during the control period and during the experimental period immediately preceding arousal (heart rate and blood pressure-five cardiac cycles; respiratory frequency and integrated diaphragm activity - five respiratory cycles if possible; oxygen saturation -at arousal) for QS and AS; these values were used for statistical analysis. To analyze the data statistically, we performed a Student's paired $t$ test to determine if the $\mathrm{FIO}_{2}$ significantly affected the time to arousal. A one-way analysis of variance for repeated measure of the same variable was used to determine if the $\mathrm{FIO}_{2}$ affected baseline cardiopulmonary variables or their change prior to arousal following UAO (10). If there was a significant difference, a Newman-Keuls test was performed to determine which means were statistically different.

Nine lambs (three of the above mentioned lambs and six lambs that were instrumented in a similar fashion for another study) were also studied to determine changes in arterial blood gases and $\mathrm{pH}$ at 15 -s intervals following UAO for 1 min during quiet wakefulness. This was done so that we could estimate changes in arterial carbon dioxide and $\mathrm{pH}$ during UAO.

\section{RESULTS}

As we have previously found $(8,11,12)$, arousal occurred from both sleep states during UAO (Fig. 2) but was significantly delayed during AS compared to QS. Two of the 10 lambs studied (Fig. 3) had mean arousal times during QS on room air that were significantly longer than we have previously observed [Ref. 8, 7 $\pm 2 \mathrm{~s}$ (mean $1 \pm \mathrm{SD}$ ); Ref. 11, $7 \pm 1 \mathrm{~s}$; Ref. 12, $6 \pm 2 \mathrm{~s}$. One lamb (+) had a mean arousal time of 13 s and the other $\left(^{*}\right)$ had a mean arousal time of $18 \mathrm{~s}$; these mean times are greater than or equal to 3 SDs from our previously observed mean arousal times. Since the present study was designed to investigate the mechanism of the normal arousal response to UAO in lambs, 


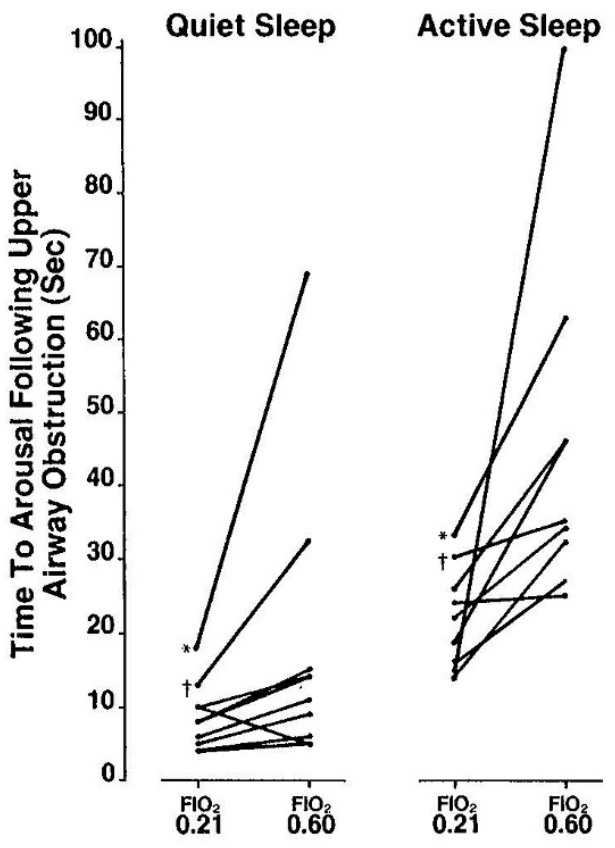

Fig. 2. Effect of inspired oxygen concentration on the time to arousal following upper airway obstruction in QS and AS in 10 lambs. * and † indicate two lambs that were considered separately because of their delayed arousal responses on room air in QS.

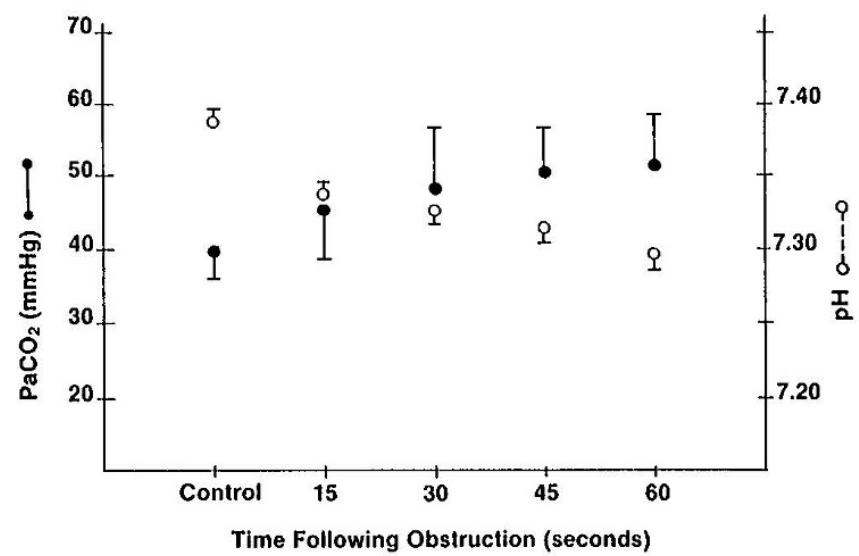

Fig. 3. Effect of upper airway obstruction on arterial carbon dioxide tension and $\mathrm{pH}$ in nine lambs during wakefulness.

Table 1. Effects of hyperoxia on arousal response to upper airway obstruction in lambs*

\begin{tabular}{lcclll}
\hline & \multicolumn{2}{c}{ Quiet sleep } & & \multicolumn{2}{c}{ Active sleep } \\
\cline { 2 - 3 } \cline { 5 - 6 } \cline { 5 - 6 } \cline { 5 - 6 } & \multicolumn{2}{c}{$\mathrm{FIO}_{2}$} & & \multicolumn{2}{c}{$\mathrm{FlO}_{2}$} \\
\cline { 2 - 3 } & 0.21 & 0.60 & & 0.21 & 0.60 \\
\hline Time to arousal (s) & $7 \pm 2$ & $10 \pm 4$ & & $21 \pm 6$ & $44 \pm 25 \dagger$ \\
Control $\mathrm{SaO}_{2}(\%)$ & $90 \pm 5$ & $97 \pm 1$ & & $92 \pm 2$ & $97 \pm 1$ \\
Arousal $\mathrm{SaO}_{2}(\%)$ & $87 \pm 7$ & $97 \pm 1 \dagger$ & & $78 \pm 10$ & $94 \pm 8 \dagger$ \\
\hline
\end{tabular}

* Values are expressed as mean $\pm 1 \mathrm{SD}$ for $n=8$ in quiet sleep and $n$ $=7$ in active sleep. The nuchal electromyogram did not function properly in a lamb and therefore, data were not obtained in AS.

$+p<0.05$ for the effect of hyperoxia on the response. these two animals will be considered separately, as we believe their response is different from the other lambs and may be due to a different mechanism. This possibility will be explored in the discussion.

Hyperoxia significantly $(p<0.05)$ delayed the time to arousal during UAO in AS but had little effect in QS (Table 1). Hemoglobin oxygen saturation at arousal during UAO was significantly increased during increased $\mathrm{FIO}_{2}$ compared to room air in both sleep states.

Hyperoxia did not significantly affect control blood pressure or heart rate in QS or AS (Table 2). Heart rate decreased significantly during UAO before arousal in AS on room air and increased $\mathrm{FIO}_{2}$; the decrease was significantly greater on room air. UAO did not produce any statistically significant changes in blood pressure (systolic or diastolic) during QS or AS. As we have previously found, heart rate and blood pressure were decreased in AS compared to QS (13).

Hyperoxia did not significantly affect control respiratory rate in QS or AS (Table 3). Respiratory rate decreased significantly during UAO before arousal in QS and AS.

The increase in arterial carbon dioxide tension and the decrease in $\mathrm{pH}$ following UAO for $1 \mathrm{~min}$ in nine lambs are shown in Figure 3. These data are included to aid in the discussion of the possible mechanisms of arousal during hyperoxia.

\section{DISCUSSION}

Our study provides new information about the mechanism(s) of arousal from sleep during UAO in newborn lambs. Hypoxemia appears to primarily initiate the arousal response during AS but not during QS. Furthermore, our data provide evidence that there are a variety of potential mechanisms capable of initiating arousal.

During AS, the lengthy delay in the arousal response during increased $\mathrm{FIO}_{2}$ (i.e. $21 \pm 6$ to $44 \pm 25 \mathrm{~s}$ ) indicates that arousal during UAO is primarily initiated by decrease in arterial oxygen and most likely mediated by the peripheral chemoreceptors. However, the persistently elevated $\mathrm{SaO}_{2}(94 \pm 8 \%)$ at arousal during increased $\mathrm{FIO}_{2}$ suggests that other mechanisms, possibly hypercapnia resulting from prolonged apnea $\left(\mathrm{PaCO}_{2} \sim 50 \mathrm{~mm}\right.$ $\mathrm{Hg}$; Fig. 3), will initiate the arousal response if the hypoxic stimulus is removed.

Increased $\mathrm{FIO}_{2}$ slightly increased the time to arousal during QS (i.e. $7 \pm 2$ to $10 \pm 4 \mathrm{~s}$ ), although the change was not statistically significant. The minimal delay in the arousal response indicates that hypoxemia does not primarily initiate arousal in response to UAO in QS as it does in AS. The $\mathrm{SaO}_{2}$ did not change prior to arousal during increased $\mathrm{FIO}_{2}$ in QS. Again, $\mathrm{PaCO}_{2}$ or the arterial $\mathrm{pH}$ could initiate the arousal response in this circumstance, but the change in $\mathrm{PaCO}_{2}$ and $\mathrm{pH}$ are very small after obstruction for a brief $10 \mathrm{~s}$ (Fig. 3). This suggests that other mechanisms, perhaps lung and airway mechanoreceptors, are primarily responsible for initiating arousal from sleep during UAO in QS.

Our results indicate that several mechanisms are potentially important in initiating the arousal response from sleep during UAO. This concept should not be altogether surprising in view of the essential nature of respiration in maintaining life. The data from the two animals that had delayed arousal responses during QS in room air (Fig. 2) may, indeed, illustrate a situation where the usual mechanism for initiating arousal during QS is defective. The eventual arousal of both animals, although delayed, demonstrates a "back-up" level of defense. In these two animals, it appears that the early mechanical stimulus did not initiate arousal during QS but that arousal was eventually initiated by a decrease in arterial oxygen. The mean times to arousal were 18 and $13 \mathrm{~s}$ in these two animals which is greater than or equal to 3 SDs from the mean arousal times we have observed in response to UAO during QS on room air in three other studies 
Table 2. Effects of hyperoxia on cardiovascular response to upper airway obstruction in lambs*

\begin{tabular}{|c|c|c|c|c|}
\hline & \multicolumn{2}{|c|}{ Quiet sleep } & \multicolumn{2}{|c|}{ Active sleep } \\
\hline & \multicolumn{2}{|c|}{$\mathrm{FIO}_{2}$} & \multicolumn{2}{|c|}{$\mathrm{FlO}_{2}$} \\
\hline & 0.21 & 0.60 & 0.21 & 0.60 \\
\hline Control heart rate (beats/min) & $182 \pm 13$ & $175 \pm 21$ & $157 \pm 14$ & $156 \pm 15$ \\
\hline Arousal heart rate (beats/min) & $165 \pm 15$ & $166 \pm 15$ & $123 \pm 33 \dagger$ & $136 \pm 19 \dagger, \ddagger$ \\
\hline \multirow[t]{2}{*}{ Control blood pressure $(\mathrm{mm} \mathrm{Hg})$} & $103 \pm 12$ & $105 \pm 15$ & $92 \pm 16$ & $94 \pm 17$ \\
\hline & $73 \pm 13$ & $73 \pm 13$ & $63 \pm 12$ & $62 \pm 12$ \\
\hline \multirow[t]{2}{*}{ Arousal blood pressure $(\mathrm{mm} \mathrm{Hg})$} & $108 \pm 14$ & $105 \pm 17$ & $97 \pm 18$ & $100 \pm 17$ \\
\hline & $74 \pm 13$ & $75 \pm 11$ & $63 \pm 9$ & $67 \pm 14$ \\
\hline
\end{tabular}

* Values are expressed as mean \pm 1 SD for $n=8$ in quiet sleep and $n=7$ in active sleep.

$\uparrow p<0.05$ for change in heart rate during upper airway obstruction prior to arousal.

$\$ p<0.05$ for effect of hyperoxia on the heart rate response.

Table 3. Effects of hyperoxia on respiratory response to upper airway obstruction in lambs*

\begin{tabular}{|c|c|c|c|c|}
\hline & \multirow{2}{*}{\multicolumn{2}{|c|}{$\frac{\text { Quiet sleep }}{\mathrm{FIO}_{2}}$}} & \multirow{2}{*}{\multicolumn{2}{|c|}{$\frac{\text { Active sleep }}{\mathrm{FIO}_{2}}$}} \\
\hline & & & & \\
\hline & 0.21 & 0.60 & 0.21 & 0.60 \\
\hline $\begin{array}{l}\text { Control respiratory rate } \\
\text { (breaths } / \mathrm{min} \text { ) }\end{array}$ & $41 \pm 8$ & $37 \pm 8$ & $47 \pm 7$ & $41 \pm 7$ \\
\hline $\begin{array}{l}\text { Arousal respiratory rate } \\
\text { (breaths } / \mathrm{min} \text { ) }\end{array}$ & $33 \pm 81$ & $28 \pm 8 \dagger$ & $40 \pm 7 \dagger$ & $30 \pm 7 \dagger$ \\
\hline Increased diaphragm activity & $28 \pm 20$ & $30 \pm 26$ & $27 \pm 21$ & $62 \pm 34$ \\
\hline
\end{tabular}
at arousal (\%)

* Values are expressed as mean \pm 1 SD for $n=8$ in quiet sleep and $n$ $=7$ in active sleep for respiratory rate and $n=7$ in quiet sleep and $n=$ 6 in active sleep for diaphragm activity.

$\dagger p<0.05$ for change in respiratory rate during upper airway obstruction prior to arousal.

$(8,11,12)$. The mean $\mathrm{SaO}_{2}$ at arousal on room air were 63 and $80 \%$ in these two animals compared to $87 \pm 7 \%$ in the other animals (Table 1). Furthermore, mean arousal times were delayed from 18 to $63 \mathrm{~s}$ in one animal and 13 to $32 \mathrm{~s}$ in the other animal by increasing the $\mathrm{FIO}_{2}$.

Previous studies on adult humans and dogs have provided mixed results concerning the mechanism of the arousal response from sleep to $\operatorname{UAO}(6,7,14)$. Two studies have provided evidence that the arousal response following UAO is initiated by a decrease in arterial oxygen in both QS and AS $(6,7)$. Motta and Guilleminault (6) found that supplemental oxygen, administered in sufficient quantities to increase the arterial oxygen tension to greater than 120 torr, increased the duration of apneas in QS and AS in four male patients with the sleep apnea syndrome. Bowes et al. (7) found that carotid body denervation impaired the arousal response to UAO (tracheal obstruction) during QS and AS in two chronically tracheostomized adult dogs. To the contrary, Issa and Sullivan (14) found that arousal from sleep in response to UAO (nasal occlusion) in healthy adult humans occurred sooner in AS than in QS and the mean changes in $\mathrm{SaO}_{2}$ were $1.2 \pm 0.2$ and $4.2 \pm 0.6 \%$, respectively. The reason for the differences between these data is not easily explained. However, it may be due to differences between species, to differences in the site and method of UAO, or possibly due to the fact that some of their subjects had been repeatedly exposed to various respiratory stimuli.

Few studies are available that provide specific information about the arousal response from sleep following UAO in human newborns. Frantz et al. (15), in an investigation of the progressive respiratory response to airway occlusion in QS and AS, found that UAO (by occluding the port of a mask on the infants face) for $10 \mathrm{~s}$ did not cause a noticeable effect on the EEG or sleep state of full-term infants. To the contrary, Rodenstein et al. (16), in an investigation to determine whether or not infants are obligatory nasal breathers, found that nasal occlusion produced an immediate arousal reaction from QS in three term infants. Lastly, Stark and Thach (17), in an investigation of the characteristics of spontaneous restoration of air flow after UAO during neck flexion, found that UAO produced by neck flexion usually did not cause arousal in full-term infants; however, arousal did affect the pattern of restoration of airflow. In the absence of arousal, reopening of the airway was delayed and incomplete. In contrast, when arousal did occur, reopening of the airway was immediate and complete.

If we just focus on data from newborn lambs, the following information is available. First, the arousal response to UAO does not appear to be influenced by the site of obstruction. HendersonSmart and Read (18) found that arousal from sleep in response to UAO (nasal occlusion) on room air occurred after a few occluded breaths in QS but did not occur within $10 \mathrm{~s}$ of occlusion in AS. Their data are similar to ours where UAO was produced by tracheal occlusion (8) (Table 1). Second, the $\mathrm{SaO}_{2}$ at arousal during $\mathrm{UAO}$ appears to be higher than the $\mathrm{SaO}_{2}$ at arousal during isocapneic hypoxemia (19) or hypocapneic hypoxemia (20) produced by breathing hypoxic gas mixtures. This suggests that either hypercapnia or perhaps mechanical stimuli interact with hypoxemia to cause arousal from sleep. However, this requires further investigation.

Heart rate decreased during UAO before arousal in AS on room air and hyperoxia. However, it is important to note that hyperoxia attenuated the effect of UAO on heart rate even though the time to arousal was twice as long on hyperoxia as on room air. The decrease in heart rate on room air during UAO most likely resulted from hypoxemia $\left(\mathrm{SaO}_{2} 78 \pm 10 \%, \mathrm{PaCO}_{2}\right.$ approximately 45 torr) and stimulation of the peripheral chemoreceptors in the absence of lung expansion $(20,21)$. The decrease in heart rate on increased $\mathrm{FIO}_{2}$ during UAO most likely resulted from hypercapnia $\left(\mathrm{SaO}_{2} 94 \pm 8 \%, \mathrm{PaCO}_{2}\right.$ approximately 50 torr) during the long apneic period.

Blood pressure tended to increase before arousal in AS during both room air and hyperoxia, although the change did not reach statistical significance (Table 2). We have previously shown that acute increases in blood pressure of a larger magnitude are capable of causing arousal from both QS and AS (23). The possibility that changes in hemodynamics associated with UAO may participate in initiating the arousal response warrants further investigation.

In AS, the integrated diaphragm activity tended to increase more during UAO in increased $\mathrm{FIO}_{2}$ than during UAO in room air. This suggests that hypercapnia may be a greater respiratory stimulus than hypoxemia during AS. However, further investigation of the respiratory response to chemical stimuli in newborn lambs is required. 
In summary, we have provided evidence that the primary mechanism of arousal from sleep during UAO is different in QS and AS. We suspect that the initiation of arousal from sleep is caused by an interaction of several mechanisms to maintain ventilation. The predominant mechanism apparently varies in different sleep states. This may possibly be due to the effect of sleep state on the arousal threshold to various stimuli or to the effect of sleep state on the latency of the arousal response once an arousal threshold has been reached.

\section{REFERENCES}

1. Phillipson EA, Sullivan CE 1978 Arousal: the forgotten response to respiratory stimuli. Am Rev Respir Dis 11 8:807-809

2. Read DJC. Henderson-Smart DJ 1984 Regulation of breathing in the newborn during different behavioral states. Ann Rev Physiol 46:675-685

3. Southall DP. Richard's J, Brown DJ. Johnston PGB, DeSwiet M. Shinebourne EA 1980 24-hour recordings of ECG and respiration in the newborn infant with findings related to sudden death and unexplained brain damage in infancy. Arch Dis Child 55:7-16

4. van der Hal AL. Rodriguez AM, Sargent CW, Platzker ACG, Keens TG 1985 Hypoxic and hypercapneic arousal responses and prediction of subsequent apnea in apnea of infancy. Pediatrics 75:848-854

5. Guntheroth WG 1983 Arrhythmia, apnea or arousal? In: Tildon WT, Rolder LM, Stcinschneider A (eds) Sudden Infant Death Syndrome. Academic Press, London, pp 263-269

6. Motta J. Guilleminault C 1978 Effects of oxygen administration in sleepinduced apnca. In: Guilleminaut C. Dement WC (eds) Sleep Apnea Syndromes. Alan R Liss, New York, pp 137-144

7. Bowes C. Townsend ER. Bromley SM, Kozar LF, Phillipson EA 1981 Role of the carotid body and of afferent vagal stimuli in the arousal response to airway occlusion in sleeping dogs. Am Rev Respir Dis 123:644-647

8. Fewell JE 1985 Arousal and cardiorespiratory responses to upper airway obstruction during sleep in lambs. In: Jones CT. Nathanielsz PW (eds) The
Physiological Development of the Fetus and Newborn. Academic Press, London, pp 217-222

9. Fewell JE, Williams BJ, Hill DE 1984 Behavioral state influences the cardiovascular response to haemorrhage in lambs. J Dev Physiol 6:339-348

10. Winer BJ 1971 Single-factor experiments having repeated measures on the same elements. In: Statistical Principles in Experimental Design. McGrawHill Book Company, New York, pp 261-308

11. Fewell JE, Szabo JS. Taylor BJ, Williams BJ 1985 Habituation of the arousal response to upper airway obstruction in lambs. J Physiol 371:234P

12. Fewell JE 1986 Influence of short-term sleep fragmentation on the arousal response to upper aiway obstruction in lambs. Clin Res $34: 255 \mathrm{~A}$

13. Fewell JE, Williams BJ, Hill DE 1985 Control of blood pressure during sleep in lambs. Sleep 8:254-260

14. Issa FG, Sullivan CE 1983 Arousal and breathing responses to airway occlusion in healthy sleeping adults. J Appl Physiol 55:1113-1119

15. Frantz ID, Adler SM, Abroms IF, Thach BT 1976 Respiratory response to airway occlusion in infants: sleep state and maturation. $\mathrm{J}$ Appl Physiol 41:634-638

16. Rodenstein DO, Perlmutter N, Stanescu DC 1985 Infants are not obligatory nasal breathers. Am Rev Respir Dis 131:343-347

17. Stark AR, Thach BT 1981 Recovery of airway patency after obstruction in normal infants. Am Rev Respir Dis 123:691-693

18. Henderson-Smart DJ, Read DJC 1976 Depression of respiratory muscles and defective responses to nasal obstruction during active sleep in the newborn. Aust Paediatr J 12:261-266

19. Henderson-Smart DJ, Read DJC 1979 Ventilatory responses to hypoxaemia during sleep in the newborn. J Dev Physiol 1:195-208

20. Fewell JE. Baker SB 1986 The arousal response from sleep to rapidly developing hypoxemia in lambs: threshold vs. latency. Physiologist (in press)

21. de Burgh Daly M 1972 Interaction of cardiovascular reflexes. In: Gilliland I Francis $\mathbf{J}$ (eds) The Scientific Basis of Medicine Annual Reviews. The Athlone Press, University of London, London, pp 307-332

22. Fewell JE, Ramick RA, Taylor BJ 1986 Influence of the ventilatory response on the cardiovascular response to hypoxemia in lambs. Pediatr Res 20:368A

23. Fewell JE. Johnson P 1984 Acute increases in blood pressure cause arousal from sleep in lambs. Brain Res 311:259-265 